THE survival of auditory neurones depends on the continued supply of trophic factors. Early postnatal spiral ganglion cells (SGC) in a dissociated cell culture were used as a model of auditory innervation to test the trophic factors leukaemia inhibitory factor (LIF) and neurotrophin-3 (NT-3) for their ability, individually or in combination, to promote neuronal survival. The findings suggest that LIF supports neuronal survival in a concentration-dependent manner. Moreover LIF potentiated NT-3-mediated spiral ganglion neuronal survival in a synergistic fashion.

Key words: Auditory neurones; Cytokine; Neuronal degeneration; Neurotrophic effects; Neurotrophin; Pharmacological therapy

\section{LIF potentiates the NT-3-mediated survival of spiral ganglia neurones in vitro}

\author{
P. L. Marzella, CA G. M. Clark, \\ R. K. Shepherd, P. F. Bartlett ${ }^{1}$ \\ and T. J. Kilpatrick ${ }^{1}$
}

Department of Otolaryngology, University of Melbourne, Royal Victorian Eye and Ear Hospital, 32 Gisborne Street, East Melbourne Australia 3002; ${ }^{1}$ Neuroimmunology Laboratory, The Walter and Eliza Hall Institute of Medical Research, Parkville Australia 3052

${ }^{\mathrm{CA} C o r r e s p o n d i n g ~ A u t h o r ~}$

\section{Introduction}

Degeneration of spiral ganglion cells (SGC) is one of the most common histopathological correlates of sensorineural hearing loss. ${ }^{1}$ Hair cells within the cochlea produce and supply trophic factors: ${ }^{2}$ when cochlear hair cells are lost as a result of trauma, disease or ageing, there is a secondary wave of SGC degeneration, ${ }^{3}$ suggesting that the continued supply of growth factors is responsible for maintaining neuronal integrity.

Brain-derived neurotrophic factor (BDNF), neurotrophin-3 (NT-3) and neurotrophin 4/5 (NT4/5) are members of a family of growth factors reported to exert activity on SGC, providing protection against cisplatin toxicity and promoting neuronal survival. ${ }^{4}$ In addition, BDNF and NT-3 have been reported to play a role in the development and patterning of developing auditory neurones. ${ }^{5,6}$ Findings in mutant mice null for NT-3 report a significant loss of SGC. ${ }^{6}$ Moreover, studies of neurotrophin receptors (trkB and trkC), revealed that spiral ganglia neurones in $\operatorname{trkB}^{-/}$; trkC $^{-/-}$double mutant mice were reduced by $61 \%$ compared with wild type. ${ }^{7}$

The cytokine and growth factor ciliary-derived neurotrophic factor (CNTF) has also been reported to have trophic effects on SGC. ${ }^{8,9}$ CNTF was found to increase the survival of auditory neurones in dissociated cell cultures. ${ }^{9}$ In addition, there is evidence to suggest that NTs and cytokines act additively upon SGC. Indeed, a combination of CNTF and BDNF was found to be more effective in promoting the survival of neurones in dissociated cell cultures of 5-day-old rat than either factor individually. ${ }^{9}$ By contrast, in rat spiral ganglion explant treatment with NT-3 gave maximal survival; this remained unchanged when either BDNF or CNTF was added. ${ }^{8}$

Leukaemia inhibitory factor (LIF) is a cytokine structurally homologous to CNTF. ${ }^{10}$ Furthermore, the receptors for LIF and CNTF also share two identical receptor components, which are believed to induce their overlapping biological activity. ${ }^{10}$ Because LIF exhibits activity on several neuronal classes, ${ }^{10-13,15}$ and CNTF has demonstrated activity on $\mathrm{SGC}^{8,9}$ it is reasonable to assume that $\mathrm{LIF}$ would also have trophic activity on SGC. In addition, a limiting factor to the heterodimerisation of the CNTF receptor complex is the CNTF $\alpha$-receptor (CNTFR $\alpha$ ) component, which is restricted in its distribution. ${ }^{10}$ By contrast, LIF only requires the receptor components gp130 and LIFR $\beta$ for signal transduction. The latter two receptor components are widely distributed, ${ }^{10}$ suggesting that LIF may have a greater number of targets (cells or receptors) than CNTF. The distribution of CNTFR $\alpha$ in the cochlea is unknown, but if its distribution in this organ is restricted in comparison to gp130 and LIFR $\beta$ it is possible that LIF may have greater potency upon SGC and surrounding cells than CNTF. 
We therefore tested whether LIF could potentiate neuronal survival in the mammalian cochlea. In addition, we assessed whether NT-3 and LIF acted in concert in either an additive or synergistic manner to potentiate cochlear neuronal survival.

\section{Materials and Methods}

Culture of auditory neurones: Five-day-old (P5) rat pups (Wistar) were cooled then rapidly decapitated, the heads were rinsed in $70 \%$ alcohol and under aseptic conditions the skull was opened longitudinally. The temporal bone was identified and the bony capsule of the inner ear removed and placed in HEPES buffered Eagle's media (HEM). The cochleae were dissected, and after careful removal of the organ of Corti the remaining gelatinous modiolus was digested in HEM, containing $0.025 \%$ trypsin (Sigma) and $0.001 \%$ DNase (Sigma) $\left(30 \mathrm{~min}\right.$ at $37^{\circ} \mathrm{C}$ ). Trypsinisation was terminated by the addition of $1 \mathrm{ml}$ fetal bovine serum (FBS). Digested cochleae were centrifuged $(1500 \times g$ for $5 \mathrm{~min}$ at room temperature $[R T]$ ) and the pellet was gently triturated in HEM containing $0.001 \%$ DNase. The SGC suspension was again centrifuged $(1500 \times g$ for $5 \mathrm{~min}$ at RT) and the pellet resuspended in Dulbecco modified Eagle's medium (DMEM) with N1 supplement and glucose adjusted to a final concentration of $4.5 \mathrm{~g} / \mathrm{l}$.

The dissociated SGC suspension was pre-plated in $35 \mathrm{~mm}$ tissue culture plates (Falcon; $30 \mathrm{~min}$ at $37^{\circ} \mathrm{C}$, $10 \% \mathrm{CO}_{2}$ ). The supernatant of the enriched SGC was collected and a cell count was performed on $10 \mu \mathrm{l}$ of SGC suspension. The SGC suspension was then plated in 96-well culture plates (Falcon), previously coated with poly-L-lysine $(20 \mu \mathrm{g} / \mathrm{ml})$ and laminin $(0.01 \mathrm{mg} / \mathrm{ml})$ at a density of $1 \times 10^{4}$ cells/well, containing an average of $518 \pm 6$ neurones. Cell cultures were maintained at $37^{\circ} \mathrm{C}$ in $10 \% \mathrm{CO}_{2}$ for 3 days in $200 \mu \mathrm{l}$ serum free media (DMEM + N1 supplement $+4.5 \mathrm{~g} / 1$ glucose). Growth factors were added to the medium at time of plating at a range of concentrations. To determine the initial seeded number of SGC/well a separate plate was incubated at $37^{\circ} \mathrm{C}$ in $10 \% \mathrm{CO}_{2}$ for $4 \mathrm{~h}$, and the cells were then fixed and immunostained.

Immunocytochemistry: Immunostaining used the avidin-biotin complex (ABC) method (Vectastain kit). The cultures were fixed in $100 \%$ methanol $(30 \mathrm{~min})$ then rinsed in phosphate buffered saline (PBS). To prevent non-specific binding the cultures were pretreated with $2 \%$ FBS in PBS (30 min at RT) then incubated with the primary antibody: anti-200 $\mathrm{kDa}$ neurofilament ( $\alpha \mathrm{NF} 200$ rabbit Ab 1:20 dilution, $\mathrm{RT}$ for $30 \mathrm{~min}$ ). The cells were rinsed with $2 \% \mathrm{FBS}$ in PBS, then reacted with the biotinylated secondary antibody (anti-rabbit in 2\% FBS) and subsequently with $A B C$ reagents according to the manufacturer's protocol. Following this step the cultures were stained for $5 \mathrm{~min}$ at $\mathrm{RT}$ with diaminobenzidine (DAB; 1 tablet in $10 \mathrm{ml}$ PBS with $30 \mu \mathrm{H}_{2} \mathrm{O}_{2}$ ). Surviving neurones were defined as cells whose somas immunostained with the $\alpha$ NF 200 antibody and possessed neuritic projections with a length equal to at least three times the width of the neuronal soma. To measure neuronal survival all the immunostained neurones in each well were counted. Experiments were repeated four times in which there were four wells for each given concentration of NTs or combination thereof. The data were analysed for significance using ANOVA on Ranks and Student-Newman-Keuls method for multiple comparison. The care and use of the animals reported on in this study were approved by the Animal Experimentation Ethics Committee of the RVEEH and performed in accordance with the principles of the NHMRC of Australia.

\section{Results}

Dissociated SGC were plated at $10^{4}$ cells/well with a mean $( \pm$ s.e.m.) seed number of $518 \pm 6$ neurones per well. After 3 days in vitro the average number of viable cells (or cells with projections) in the untreated wells had decreased to $11 \pm 2$ cells per well, representing a survival rate of $2.1 \%$ compared with the number of neurones present $4 \mathrm{~h}$ after plating (seed). The addition of LIF promoted the survival of SGC in a concentration-dependent manner, with a significant increase in neuronal survival detected at concentrations as low as $0.1 \mathrm{ng} / \mathrm{ml}$ compared with the untreated wells (Fig. 1). Maximum neuronal survival using LIF alone was at $10 \mathrm{ng} / \mathrm{ml}(54 \pm 5$ cells/well $)$. At higher concentrations $(100 \mathrm{ng} / \mathrm{ml})$, there was a significant decrease in the survival of SGC $(p<0.05$; StudentNewman-Keuls pairwise comparison).

When used concurrently with NT-3, LIF retained a concentration-dependent survival promoting efficacy, with a maximal survival promoting effect at a concentration of $10 \mathrm{ng} / \mathrm{ml} / 50 \mathrm{ng} / \mathrm{ml}$. In addition, LIF and NT-3 showed significant survival-promoting activity at concentrations as low as $0.1 \mathrm{ng} / \mathrm{ml} / 0.1$ $\mathrm{ng} / \mathrm{ml}$ (LIF/NT-3). When combined, the survivalpromoting action of LIF and NT-3 appeared to be synergistic (Fig. 1), since the average number of neurones surviving in the presence of both factors was 1.6-fold greater than the aggregate of the maximal increases recorded when using each factor alone.

\section{Discussion}

This study indicates that LIF individually or in combination with NT-3 can promote survival of SGC 


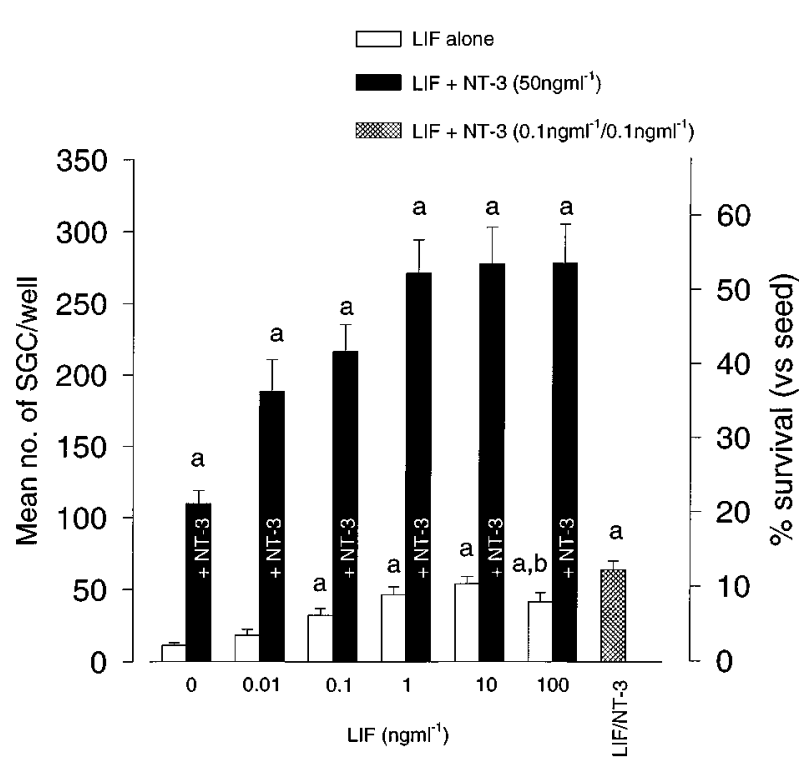

FIG. 1. Effects of leukaemia inhibitory factor (LIF) and neutrophin3 (NT-3) on the survival of P5 rat spiral ganglia after $72 \mathrm{~h}$ in vitro. The total number of neurofilament antibody-stained spiral ganglia neurones counted in each well (left $y$-axis) or as a percentage of survival (right y-axis) is expressed as a function of the concentration of neurotrophic factor or combination of factors (x-axis). Each condition is represented by four culture wells repeated in four experiments, $n=16$ for each data bar. Results are expressed as mean \pm s.e.m. Seed number of neurones $518 \pm 6$. ${ }^{a} p<0.001$ between treatment condition and control wells; ${ }^{b} p<0.001$ between $100 \mathrm{ng} / \mathrm{ml}$ and $10 \mathrm{ng} / \mathrm{ml}$ LIF.

in culture. At present the role of LIF in the auditory system or under what conditions it may be expressed is not known. LIF's known pleiotropic activity across other classes of neurones ${ }^{10-13,15}$ suggests that it may also have various roles within the auditory system.

Previously, $\left.{ }^{125} \mathrm{I}\right] \mathrm{LIF}$ binding sites have been detected in both neural crest- and placode-derived sensory ganglia. ${ }^{12}$ Because SGC derive from the otic placode, while Schwann cells and supporting cells are of neural crest origin, ${ }^{14}$ it is possible that during embryogenesis these cells could also express [125I]LIF binding sites, suggesting that LIF may have a developmental role in the cochlea. LIF may also have an action on SGC in response to injury: this hypothesis is supported by another study reporting increased retrograde transport in axotomized neurones. ${ }^{16}$ At present it is also unknown whether LIF may also have a target-derived neurotrophic role (i.e. whether it is present in hair cells). Although a recent study shows that the CNTF family of factors and their respective receptors are found in the postnatal cochlea ${ }^{17}$ we await the results of further in situ studies to elucidate whether LIF may also have a target-derived neurotrophic role within the adult cochlea.

A previous study reported that NT-3 treatment resulted in maximal survival of rat SGC, which remained unaffected by the concomitant addition of either BDNF or CNTF. ${ }^{8}$ By contrast, we report that LIF can potentiate the NT-3-induced survival of SGC by up to 1.6 -fold. It is unclear why LIF has greater efficacy than CNTF or BDNF in potentiating NT-3-induced survival of SGC. However, the widespread distribution of LIF receptor components across other classes of neurones ${ }^{10}$ suggests that LIF receptor may be broadly expressed on SGC and/or on surrounding cells. This broad distribution of the LIF receptor components may underpin the ability of LIF to potentiate NT-3-induced survival of SGC.

Furthermore, it is undetermined whether the potentiating effect of LIF upon NT-3-induced survival is occurring on the same neurones. The converging second messenger pathways for the neural cytokines and NTs. ${ }^{10}$ and the synergistic action demonstrated in these studies suggest that LIF and NT3 may indeed be acting on the same SGC to potentiate each other's survival effects. Conversely, in dissociated cell cultures other non-neuronal cells (i.e. fibroblast and glial cells) proliferate, and therefore, it is possible that LIF may act indirectly via these cells as well as exert direct action on the SGC themselves. In addition, studies with antibodies directed at the trkB and trkC receptors for the NTs revealed that in vitro some populations of SGC are NT-independent. ${ }^{4}$ Thus the population of surviving neurones may include SGCs targeted by both factors, SGCs supported by only one of the factors and SGCs indirectly affected by LIF and NT-3. Double labelling studies may elucidate the site(s) of LIF-receptor complexes and thus help determine the site(s) of action.

\section{Conclusion}

We report that the cytokine LIF displays trophic activity and improves the NT-3-induced neuronal survival in dissociated SGC cultures. These data support the theory that NTs and cytokines act concomitantly on inner ear innervation in the early postnatal period, when the complex pattern of adult innervation is being established. In situ hybridization studies will determine transcription levels of the LIF receptor components within the auditory system, and thus elucidate where LIF may be acting and whether there are developmental periods of critical expression. Moreover, they will help determine if there is a relationship between non-neuronal cell injury and neuronal repair.

In addition, the results suggest that a combination of several trophic factors may provide a better approach than single factor delivery when developing pharmacological therapies for auditory neurone repair. 


\section{References}

1. Otte J, Schuknecht HF and Kerr AG. Laryngoscope 88, 1231-1246 (1978).

2. Lefebvre PP, Weber T, Rigo JM et al. Hear Res 58, 185-192 (1992).

3. Spoendlin H. Ann Otol Rhinol Laryngol 93 (Suppl. 112), 76-82 (1984).

4. Zheng JL, Stewart RR and Gao WO J Neurosci 15, 5079-5087 (1995).

5. Staecker H, Van De Water TR, Lefebvre PP et al. Dev Brain Res 92, 49-60 (1996).

6. Fariñas I, Jones KR, Backus C et al. Nature 369, 658-661 (1994).

7. Minichello L, Piehl F, Vazquez E et al. Development 121, 4067-4075 (1995).

8. Staecker H, Liu W, Hartnick C et al. NeuroReport 6, 1533-1537 (1995)

9. Hartnick CJ, Staecker H, Malgrange B et al. J Neurobiol 30, 246-254 (1996).

10. Ip NY and Yancopoulos GD. Annu Rev Neurosci 19, 491-515 (1996).

11. Murphy M, Reid K, Brown MA et al. Development 117, 1173-1182 (1993).

12. Qui LQ, Bernd P and Fukada K. Dev Biol 163, 516-520 (1994).

13. Hilton DJ and Gough NM. J Cell Biochem 46, 21-26 (1991).

14. Whitehead M. Development of the cochlea. In Altschuler RA, Hoffman DW and Bobbin RP, eds. Neurobiology of Hearing, New York: Raven Press, 1986: 191-211.
15. Kwon YW, Abbondanzo SJ, Stewart CL et al. J Neurobiol 28, 35-50 (1995). 16. Hendry IA, Murphy M, Hilton DJ et al. J Neurosci 12, 3247-3434 (1992).

17. Malgrange $B$, Lefebvre PP, Rogister B, et al. Abstracts of the Association for Research in Otolaryngology. XVIIIth Midwinter Research Meeting Abs\# 18 (1997).

ACKNOWLEDGMENTS: P.L.M. is funded by the lan Potter Foundation. G.M.C. is funded by the Human Communication Research Centre of the Department of Otolaryngology, University of Melbourne. R.K.S. is a recipient of a Senior Research fellowship from The Garnett Passe and Rodney Williams Foundation. P.F.B. is funded by NH MRC. T.J.K. is a recipient of a Senior Medical Research fellowship from The Sylvia and Charles Viertel Foundation.

\section{Received 6 February 1997; accepted 6 March 1997}

\section{General Summary}

A combination of neuronal growth factors promoted the survival of auditory nerve cells in vitro in a synergistic manner. The neuronal cytokine leukaemia inhibitory factor (LIF) and the neurotrophin-3 (NT-3) were tested for their ability, individually or in combination, to promote auditory nerve cells survival. The findings suggest that treatment with LIF supports auditory nerve cell survival in a concentration-dependent manner, and potentiates NT-3-mediated auditory nerve cells survival in a synergistic fashion. The results suggest that a combination of several nerve growth factors may provide a better approach than single factor therapy when developing pharmacological therapies for the treatment of deafness. 


\section{University Library}

\section{- M M N E R VA A gateway to Melbourne's research publications}

Minerva Access is the Institutional Repository of The University of Melbourne

Author/s:

Marzella, P. L.;Clark, Graeme M.;Shepherd, R. K.;Bartlett, P. F.;Kilpatrick, T. J.

Title:

LIF potentiates the NT-3-mediated survival of spiral ganglia neurones in vitro

Date:

1997

Citation:

Marzella, P. L., Clark, G. M., Shepherd, R. K., Bartlett, P. F., \& Kilpatrick, T. J. (1997). LIF potentiates the NT-3-mediated survival of spiral ganglia neurones in vitro. NeuroReport, 8, 1641-1644.

Persistent Link:

http://hdl.handle.net/11343/27559 